\title{
Gabapentin Bioequivalence Study: Quantification by Liquid Chromatography Coupled to Mass Spectrometry
}

\section{Eduardo Abib Junior ${ }^{1,2 *}$, Luciana Fernandes Duarte ${ }^{2}$, Renata Pereira ${ }^{2}$, Joseane Montagner Pozzebon ${ }^{2}$, Deo Tosetti ${ }^{2}$ and Juliana Marise Cardoso Custódio}

${ }^{1}$ Department of Clinical Medicine, Faculty of Medical Sciences, State University of Campinas (UNICAMP), 13083-970, Campinas, SP, Brazil

${ }^{2}$ Scentryphar Clinical Research, 13020-420, Campinas, SP, Brazil

${ }^{3}$ Arrow Farmacêutica, 20251-061, Rio de Janeiro, RJ, Brazil

\begin{abstract}
The study was performed to compare the bioavailability of two gabapentin $400 \mathrm{mg}$ capsule formulation (Gabapentin from Arrow Farmacêutica S/A as test formulation and Neurontin ${ }^{\circledR}$ from Pfizer, Brazil, as reference formulation) in 26 volunteers of both sexes. The study was conducted open with randomized two period crossover design and a one week wash out period. Plasma samples were obtained over a 48 hour interval. The gabapentin was analyzed by LC/MS/MS, in the presence of pracetamole as internal standard. With plasma concentration vs. time curves, data obtained from this metabolite, the following pharmacokinetics parameters were obtained: $A U C_{0.1}$, $\mathrm{AUC}_{\text {0inf }}$ and $\mathrm{C}_{\text {max }}$. Geometric mean of gabapentin/Neurontin ${ }^{\circledR} 400 \mathrm{mg}$ individual percent ratio was $100.58 \% \mathrm{AUC}_{0 . \mathrm{t}}$, $101.35 \%$ for $A \cup C_{0 \text {-inf }}$ and $97.76 \%$ for $C_{\max }$. The $90 \%$ confidence intervals were $92.00-109.95 \%, 93.00-110.44 \%$, $88.41-108.10 \%$, respectively. Since the $90 \%$ confidence intervals for $C_{\max }, A \mathrm{CC}_{0-\mathrm{t}}$ and $\mathrm{AUC}_{0 \text {-inf }}$ were within the 80 $-125 \%$ interval proposed by Food and Drug Administration, it was concluded that gabapentin $400 \mathrm{mg}$ capsule was bioequivalent to Neurontin ${ }^{\circledR} 400 \mathrm{mg}$ capsule according to both the rate and extent of absorption.
\end{abstract}

Keywords: Gabapentin; Biological availability; Pharmacokinetics; Chromatography; Bioequivalence

\section{Introduction}

Gabapentin [1-(aminomethyl) cyclohexaneacetic acid] is an antiepileptic drug structurally related to the neurotransmitter gammaaminobutyric acid (GABA). Gabapentin is indicated as adjunctive therapy in the treatment of partial seizures with and without secondary generalization in adults with epilepsy and for the management of postherpetic neuralgia [1]. Gabapentin can be actively transported across the brain-blood barrier and the gut via the L-system amino acid transporter, which recognizes L-isoleucine, L-leucine, Lphenylalanine and L-valine [2]. The exact mode of action of GB has not yet been clearly defined. Several cellular actions have been described but are likely to be related to multiple concentration-dependent actions resulting in seizure control [3].

Maximum plasma gabapentin concentrations (mean) are attained 2 to 3 hours after a single oral $300 \mathrm{mg}$ dose in healthy volunteers. Absorption kinetics of gabapentin are dose-dependent and not dose-proportional, Possibly due to a saturable transport system. Bioavailability of a single $300 \mathrm{mg}$ oral dose of gabapentin is $60 \%$, decreasing with Increasing dose. Gabapentin has some lipophilicity and readily crosses the blood-brain barrier. Its volume of distribution is large, estimated as 50 to $60 \mathrm{~L}$ in healthy volunteers. The drug is not bound to human plasma proteins. Elimination of gabapentin is wholly accountable by renal clearance. The elimination half-life of gabapentin is about 5 to 7 hours after a single oral dose of 200 to $400 \mathrm{mg}$. Renal impairment reduces drug clearance and augments plasma gabapentin concentrations in a linear fashion $[4,5]$.

Mild adverse events, commonly fatigue, somnolence, ataxia and dizziness have been reported in about $75 \%$ of gabapentin recipients. Other events such as tremor, diplopia, nausea and vomiting were each experienced by $<10 \%$ of gabapentin recipients. The overall proportion of patients reporting adverse events during gabapentin administration has been calculated to be about $75 \%$, versus $55 \%$ for placebo [4].

The objective of this study was to compare in healthy volunteers, the pharmacokinetics profiles and evaluate the bioequivalence of one test formulation of $400 \mathrm{mg}$ capsule of gabapentin, elaborated by Arrow Farmacêutica S/A, Brazil (test formulation). The test formulation was compared to one commercial formulation of $400 \mathrm{mg}$ of gabapentin (Neurontin $^{\circledR}$ ) by Pfizer, Brazil (reference formulation).

\section{Methods}

\section{Study protocol}

The study was performed in accordance with the Helsinki Declaration and Good Clinical Practice Guideline, and informed consent was obtained from participants prior to study commencement. The clinical part of the study was condueted at Scentryphar Clinical Research (Campinas City, São Paulo, Brazil) and the bioanalytical part at Nucleus of Bioequivalence and Clinical Research/NUBEC (São Paulo, Brazil).

\section{Subjects}

Twenty six healthy volunteers of both sexes (13 males and 13 females) who were between the ages of 20 and 45 (mean \pm SEM: 28.7 \pm 7.4 years), who had heights between $150.0 \mathrm{~cm}$ and $180.0 \mathrm{~cm}(170.0 \pm$ $0.1 \mathrm{~cm})$, and who weighed between $52.0 \mathrm{~kg}$ and $87.8 \mathrm{~kg}(65.7 \pm 9.8 \mathrm{~kg})$ and within $15 \%$ of their ideal body weight were enrolled in the study. Subjects were judged eligible for enrolment in this study if they were

*Corresponding author: Eduardo Abib Junior, Scentryphar Clinical Research 885, Barão de Itapura ave, Campinas, SP - Brazil. 13020-420, Tel: (19) 3232-6350, Fax: (19) 3231-6715; E-mail: eabib@scentryphar.com

Received June 13, 2011; Accepted September 16, 2011; Published Septembe 19, 2011

Citation: Junior EA, Duarte LF, Pereira R, Pozzebon JM, Tosetti D, et al. (2011) Gabapentin Bioequivalence Study: Quantification by Liquid Chromatography Coupled to Mass Spectrometry. J Bioequiv Availab 3: 187-190. doi:10.4172/ jbb.1000083

Copyright: ( 2011 Junior EA, et al. This is an open-access article distributed unde the terms of the Creative Commons Attribution License, which permits unrestricted use, distribution, and reproduction in any medium, provided the original author and source are credited. 
in compliance with all the inclusion and exclusion criteria described in the protocol.

All the subjects provided written informed consent to participate after explaining the nature and purpose of the study. The study protocol was approved by the M.M. Assert Serviços Médicos S/A Ltda with the ethical principles described in the Declaration of Helsinki, guidelines for International Conference on Harmonization-Good clinical practices (ICH-GCP).

All volunteers were healthy as assessed by physical examination, ECG, and the following laboratory tests: blood glucose, urea, creatinine, AST, ALT, alkaline phosphatase, Gamma GT, total bilirrubin, albumin and total protein, triglycerides, total cholesterol, hemoglobin, hematocrit, total and differential white cell counts and routine urine. All subjects were negative for HIV, HBV (except for serological scare) and $\mathrm{HCV}$.

\section{Drug products}

The test formulation employed was Gabapentin $400 \mathrm{mg}$ capsule (lot number AE87) and the reference formulation was: Neurontin ${ }^{\circledR} 400$ mg capsule (lot number 835F4C).

\section{Study design}

The study was performed to compare the bioavailability of two gabapentin $400 \mathrm{mg}$ capsule formulation (Gabapentin from Arrow Farmacêutica S/A as test formulation and Neurontin ${ }^{\circledR}$ from Pfizer, Brazil, as reference formulation) under fasting conditions.

The study was conducted in an open randomized 2 period crossover balanced design with a 1 week wash out period between the doses. During each period, the volunteers were hospitalized at 8:00 pm having already had a normal evening meal, and after an overnight fast they received at 7:00 am a single $400 \mathrm{mg}$ capsule gabapentin dose of either formulation. Water $(200 \mathrm{~mL})$ was given immediately after drug administration. All volunteers were then fasted 05 hours following the drug administration, after which a standard lunch was consumed and an evening meal was provided 10 hours after dosing. No other food was permitted during the "in-house" period. Liquid consumption was permitted ad libitum after lunch but xanthine-containing drinks including tea, coffee and cola were avoided. Systolic and Diastolic arterial pressure, heart rate and temperature were recorded just before and hourly after drug administration.

Blood samples $(08 \mathrm{~mL})$ from a suitable antecubital vein were collected into heparin containing tubes before and $0.20,0.40,1.00$, $1.20,1.40,2.00,2.20,2.40,3.00,3.30,4.00,5.00,6.00,8.00,10.0,12.0$, 24.0, 36.0, 48.0 hours after administration of each gabapentin $400 \mathrm{mg}$ capsule.

\section{Drug analysis}

Blood samples were cooled in an bath and centrifuged at 3.000 $\mathrm{rpm}$ for at least $10 \mathrm{~min}$ at approximately $4^{\circ} \mathrm{C}$. At least $3 \mathrm{~mL}$ of plasma were dispensed into polypropylene tubes. Sample tubes were frozen at $-20^{\circ} \mathrm{C}$, and maintained to that temperature until analysis. All samples from a single volunteer were analyzed on the same day in order to avoid interassay variation.

Plasma concentrations of gabapentin was determined by the HPLC coupled with tandem mass spectrometry (LC/MS/MS), using acetaminophen as internal standard (IS). Plasma samples were deproteinized with acetonitrile. Briefly, $20 \mu \mathrm{L}$ of IS solution $(25 \mu \mathrm{g} / \mathrm{mL})$ and $200 \mu \mathrm{L}$ of acetonitrile were added to a $200 \mu \mathrm{L}$ aliquot of human plasma, vortex-mixed for $40 \mathrm{~s}$ and $200 \mu \mathrm{L}$ of supernatant were added to a $200 \mu \mathrm{L}$ of mobile phase. An aliquot of $10 \mu \mathrm{L}$ of the supernatant was injected into the LC/MS/MS system.

The analytical column was a Luna-C8, $150 \times 4,6 \mathrm{~mm}, 5 \mu$ (Phenomenex). The mobile phase used was a mixture of methanol and water $(30: 70 \mathrm{v} / \mathrm{v})$, containing $10 \mathrm{mM}$ acetic acid. The chromatographic run time lasted 4.0 minutes with flow rate of $1.0 \mathrm{~mL} / \mathrm{min}$, in ambient temperature.

\section{Method validation}

Quantitation was based on determination of relationship between gabapentin peaks areas and I.S. peaks areas. Selectivity was evaluated by extracting plasma samples of plasma from six different volunteers, including a lipemic and hemolysed plasma. Recoveries of gabapentin at the three QC concentrations and I.S. were determined by comparing peak areas of spiked plasma samples with the peak area in solutions prepared with the same nominal concentration. For precision (as relative standard deviation, R.S.D.) and accuracy (as relative error, R.E.) studies, samples were prepared at three QC and were analysed in the same day (intraday precision and accuracy), and analysed in 3 consecutive days (inter-day precision and accuracy).

The validated method show a Lower limit of quantification of 50 $\mathrm{ng} / \mathrm{mL}$ and linearity $>0,98$.

The intra-day accuracy and precision of the quality control samples ranged from $91.63-100.67 \%$ and $1.14-4.73 \%$. The inter-day accuracy and precision of the quality control samples ranged from 99.83$102.03 \%$ and $0.69-7.99 \%$. Similar accuracy and precision values were observed during the study sample analysis.

The recovery of gabapentin was greater than $62.87 \%$. No matrix effect on quantification was observed. The stability of gabapentin was also evaluated in post-extracted samples kept in the autosampler at room temperature $\left(23^{\circ} \mathrm{C}\right)$ for $24 \mathrm{~h}$, as well as in plasma samples kept at $-20^{\circ} \mathrm{C}$ for 89 days and after being submitted to 3 freeze-thawing cycles ( $24 \mathrm{~h}$ each cycle). All samples described above were compared to freshly prepared gabapentin samples at the same concentration level. The method was validated according to ANVISA's (National Health Surveillance Agency of Brazilian Government) criteria and used to determine the concentration of gabapentin in volunteers' plasma.

\section{Pharmacokinetic analysis and statistical analysis}

The first-order terminal elimination rate constant (Ke) was estimated by linear regression from the points describing the elimination phase on a log-linear plot, using the software $S_{A S}{ }^{\circledR}$ Institute (Version 9.1.3). Elimination half-life $\left(\mathrm{T}_{1 / 2}\right)$ was derived from this rate constant $\left(\mathrm{T}_{1 / 2}=\ln (2) / \mathrm{Ke}\right)$. The maximum observed plasma concentration $\left(\mathrm{C}_{\max }\right)$ and the time taken to achieve this concentration $\left(\mathrm{T}_{\max }\right)$ were obtained directly from the curves. The areas under the gabapentin metabolite plasma concentration versus time curves from 0 to 48 hours $\left(\mathrm{AUC}_{0-48 \mathrm{~h}}\right)$ were calculated by applying the linear trapezoidal rule. Extrapolation of these areas to infinity $\left(\mathrm{AUC}_{0-\infty}\right)$ was done by adding the value $\mathrm{C} 48 / \mathrm{Ke}$ to the calculated $\mathrm{AUC}_{0-48 \mathrm{~h}}$ (where $\mathrm{C} 48=$ plasma concentration calculated from the log-linear regression equation obtained for the estimation of Ke 48 hours after dose).

The bioequivalence between both formulations was assessed by calculating individual $\mathrm{C}_{\max }, \mathrm{AUC}_{0-48 \mathrm{~h}}, \mathrm{AUC}_{0-\infty}$ and $\mathrm{C}_{\max } / \mathrm{AUC}_{0-48 \mathrm{~h}}$ ratios (test/reference) together with their mean and $90 \%$ confidence intervals (CI) after log transformation of the data. The inclusion of the $90 \% \mathrm{CI}$ 


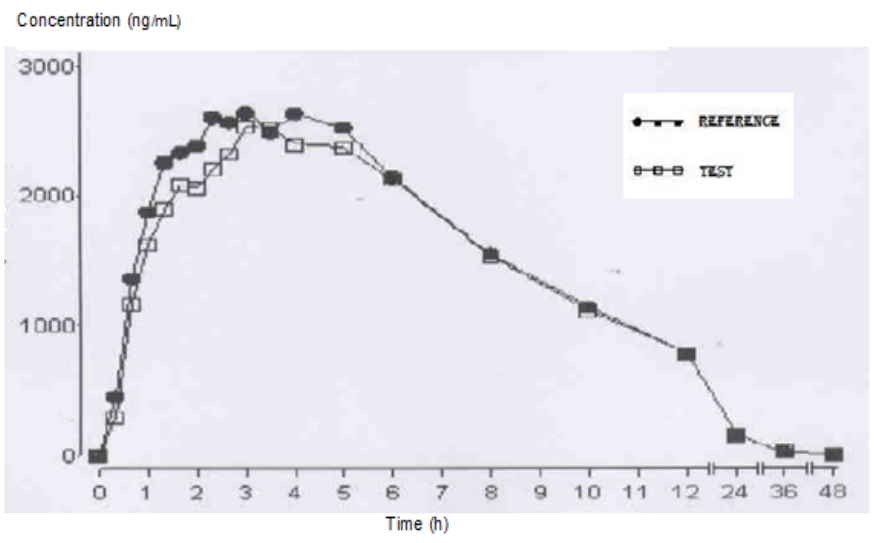

Figure 1: Figure 1: Gabapentin plasma means concentration versus time profile obtained after the single oral administration of $400 \mathrm{mg}$ of Neurontin $₫$ formulation.

for the ratio in the $80 \%$ to $125 \%$ range was analyzed by nonparametric $\left(\mathrm{SAS}^{\circledR}\right.$ Institute Version 9.1.3) and parametric (ANOVA) methods.

\section{Results}

\section{Tolerability analysis}

Gabapentin was well tolerated at the administered dose. All the biochemical parameters did not any clinical relevant alterations. No adverse effects serious were either reported or observed.

\section{Pharmacokinetic and statistical analysis}

The number of volunteers must always ensure enough statistical power to ensure the reliability of the results of the bioequivalence study. The number of volunteers in the study in question was calculated using the coefficient of variation and statistical power available in the literature. The study protocol established sufficient number of volunteers providing potential "dropouts".
The mean $( \pm \mathrm{SD})$ plasma concentration time profile of the 2 formulations, shown in Figure 1, was similar and superimposable.

Central and dispersion measures for all pharmacokinetic parameters for both formulations are shown in Table 1, and Table 2. Table 3 presents the ratios and the respective confidence intervals for bioequivalence analysis.

\section{Discussion}

Several analytical methods have been reported for the determination of gabapentin in human plasma and biological samples. The methods are based on high-performance liquid chromatography (HPLC) with UV [6,7] or fluorescence detection [8-13], capillary electrophoresis (CE) $[14,15]$, gas chromatography (GC) with flame ionization [16] or mass spectrometry (MS) [17-19], and liquid chromatography-tandem mass spectrometry (LC-MS-MS) [20-25]. The HPLC and CE methods are time-consuming because they require derivatization of gabapentin to produce a detectable chromophore. The GC methods also require derivatization of gabapentin to improve volatility and avoid column interactions. For routine analysis, derivatization step increases the time of sample preparation and cost. LC-MS-MS is currently considered the method of choice for determining gabapentin levels in biological samples because the drug can be directly detected without derivatization, thus making sample preparation time shorter.

The purpose of the present study was to develop and validate an LC-MS-MS method with simple sample preparation to determine gabapentin concentration in human plasma and to apply it to a bioequivalence study of $400 \mathrm{mg}$ gabapentin capsule in 26 healthy volunteers. A rapid, sensitive and reliable LC/MS/MS method for the determination of gabapentin in human plasma has been successfully developed and validated using deproteinized extraction as sample preparation procedure. This assay method demonstrated acceptable sensitivity (LLOQ: $50 \mathrm{ng} / \mathrm{mL}$ ), precision, accuracy, selectivity, recovery and stability, and less absolute and relative matrix effect. The validated method was successfully applied to assay human plasma samples from the bioequivalence study of gabapentin.

\begin{tabular}{|c|c|c|c|c|}
\hline & & TEST & REFERENCE & \\
\hline Parameter (unit) & Means (Median) & Standard Deviation & Means (Median) & Standard Deviation (Amplitude) \\
\hline$A \cup C_{0-t}(n g . h / m L)$ & 26754.62 & 9051.43 & 27701.48 & 12103.08 \\
\hline $\mathrm{AUC}_{0 \text {-inf }}(\mathrm{ng} \cdot \mathrm{h} / \mathrm{mL})$ & 27794.60 & 897110 & 28543.25 & 11960.75 \\
\hline $\mathrm{C}_{\text {max }},(\mathrm{ng} \cdot \mathrm{h} / \mathrm{mL})$ & 3020.35 & 949.72 & 3241.93 & 1398.00 \\
\hline $\mathrm{T}_{\max }($ median/amp) $(\mathrm{h})$ & 3.25 & 5.00 & 3.00 & 5.00 \\
\hline $\operatorname{Kel}(1 / \mathrm{h})$ & 0.13 & 0.04 & 0.14 & 0.03 \\
\hline $\mathrm{T} 1 / 2,($ median/amp) (h) & 5.31 & 7.23 & 5.49 & 5.32 \\
\hline
\end{tabular}

Table 1: Mean pharmacokinetic parameters of Gabapentin of test and reference formulation.

\begin{tabular}{|l|l|l|}
\hline & TEST & REFERENCE \\
\hline Parameter (unit) & Geometric Mean & Geometric Mean \\
\hline AUC $_{\text {0-t }}(\mathrm{ng} \cdot \mathrm{h} / \mathrm{mL})$ & 24942.67 & 24799.92 \\
\hline AUC $_{\text {-inf }}(\mathrm{ng} \cdot \mathrm{h} / \mathrm{mL})$ & 26157.87 & 25810.51 \\
\hline $\mathrm{C}_{\text {max }}$ (ng.h/mL) & 2853.74 & 2919.08 \\
\hline
\end{tabular}

Table 2: Geometric mean pharmacokinetic parameters of Gabapentin of test and reference formulation.

\begin{tabular}{|l|l|l|l|l|l|}
\hline Parameter & Ratio T/R (\%) & Lower Limit (\%) & Upper Limit (\%) & Power (\%) & Coefficient of Variation (\%) \\
\hline AUC $_{0-\mathrm{t}}(\mathrm{ng} \cdot \mathrm{h} / \mathrm{mL})$ & 100.58 & 92.00 & 10095 & 0.9878 \\
\hline AUC $_{\text {0-inf }}(\mathrm{ng} \cdot \mathrm{h} / \mathrm{mL})$ & 101.35 & 93.00 & 110.44 & 0.1894 \\
\hline $\mathrm{C}_{\max }$ (ng.h/mL) & 97.76 & 88.41 & 108.10 & 0.9005 \\
\hline Tmax (dif) $(\mathrm{h})$ & 0.17 & 0.00 & 0.67 & 0.9450 \\
\hline
\end{tabular}

Table 3: Ratios mkeans and the $90 \%$ geometric confidence interval of test and reference formulation. 
Citation: Junior EA, Duarte LF, Pereira R, Pozzebon JM, Tosetti D, et al. (2011) Gabapentin Bioequivalence Study: Quantification by Liquid Chromatography Coupled to Mass Spectrometry. J Bioequiv Availab 3: 187-190. doi:10.4172/jbb.1000083

The bioavailability of a pharmaceutical form refers to the extent and speed of absorption of the active principle in contained it. Two pharmaceutical forms are said bioequivalent when, to be administered to the same individual, in the same experimental conditions and at the same dose, showed no significant differences in relation to bioavailability. In this study two formulations of gabapentin had been evaluated. The mean ratio of parameters $\mathrm{C}_{\max }$ and $\mathrm{AUC}_{0-\mathrm{t}}$ and $90 \%$ confidence intervals of correspondents were calculated to determine the bioequivalence.

The $\mathrm{AUC}_{0-\mathrm{t}}$ and $\mathrm{AUC}_{0-\infty}$ are both recognized as an uncontaminated measurement of the extent of absorption. The present study showed that $90 \% \mathrm{CI}$ of mean $\mathrm{AUC}_{0-\mathrm{t}}$ and $\mathrm{AUC}_{0-\infty}$ (after log-transformation of individual ratios) were included into the bioequivalence range (80-125\%), consequently, the two formulations of gabapentin are equivalent for the extend of absorption.

The statistical comparison of $\mathrm{C}_{\max }, \mathrm{AUC}_{0-\mathrm{t}}$ and $\mathrm{AUC}_{0-\infty}$ clearly indicated no significant difference in the two formulations of gabapentin $400 \mathrm{mg}$ capsule. $90 \%$ confidence intervals for the mean ratio $(\mathrm{T} / \mathrm{R})$ of $\mathrm{C}_{\max }, \mathrm{AUC}_{0-\mathrm{t}}$ and $\mathrm{AUC}_{0-\infty}$ were entirely within the US Food and Drug Administration acceptance range. Based on the pharmacokinetic and statistical results of this study, we can conclude that gabapentin $400 \mathrm{mg}$ capsule (Arrow Farmacêutica S/A, Brazil) is bioequivalent to Neurontin ${ }^{\circledR} 400 \mathrm{mg}$ capsule (Pfizer, Brazil), and that then the test product can be considered interchangeable in medical practice.

\section{Acknowledgments}

This research work is financially supported by the Scentryphar Clinical Research, Brazil.

\section{References}

1. Wattananat T, Akarawut W (2009) Validated LC-MS-MS Method for the Determination of Gabapentin in Human Plasma: Application to a Bioequivalence Study. J Chromatogr Sci 47: 868-871.

2. Stewart BH, Kagler AR, Thompson PR, Bockbrader HN (1993) A saturable transport mechanism in the intestinal absorption of gabapentin is the underlying cause of the lack of proportionality between increasing dose and drug levels in plasma. Pharma Res 10: 276-281.

3. McLean MJ (1999) Gabapentin in the management of convulsive disorders Epilepsia 40: 39-50.

4. Goa KL, Sorkin EM (1993) Gabapentin: a review of its pharmacological properties and clinical potential in epilepsy. Drugs 46: 409-427.

5. Zhu Z, Neirinck L (2002) High-performance liquid chromatographic method for the determination of gabapentin in human plasma. J Chromatogr B Analyt Technol Biomed Life Sci 779: 307-312.

6. Sagirli O, Cetin SM (2006) Determination of gabapentin in human plasma and urine by high-performance liquid chromatography with UV-vis detection. J Pharm Biomed Anal 42: 618-624.

7. Jalalizadeh H, Souri E, Tehrani MB, Jahangiri A (2007) Validated HPLC method for the determination of gabapentin in human plasma using precolumn derivatization with 1-fluoro-2,4-dinitrobenzene and its application to a pharmacokinetic study. J Chromatogr B Analyt Technol Biomed Life Sci 854: 43-47.

8. Forrest G, Sills GJ, Leach JP, Brodie MJ (1996) Determination of gabapentin in plasma by high-performance liquid chromatography. J Chromatogr B Analyt Technol Biomed Life Sci 681: 421-425.

9. Tang PH, Miles MV, Glauser TA, Degrauw T (1999) Automated microanalysis of gabapentin in human serum by high-performance liquid chromatography with fluorometric detection. J Chromatogr B Analyt Technol Biomed Life Sci 727: 125-129.

10. Hassan EM, Belal F, Al-Deeb OA, Khalil NY (2001) Spectrofluorimetric determination of vigabatrin and gabapentin in dosage forms and spiked plasma samples through derivatization with 4-chloro-7-nitrobenzo-2-oxa-1,3-diazole. J. AOAC Int. 84: 1017-1024.
11. Gauthier D, Gupta R (2002) Determination of gabapentin in plasma by liquid chromatography with fluorescence detection after solid-phase extraction with a C18 column. Clin Chem 48: 2259-2261.

12. Chung TC, Tai CT, Wu HL (2006) Simple and sensitive liquid chromatographic method with fluorimetric detection for the analysis of gabapentin in human plasma. J Chromatogr A 119: 294-298.

13. Bahrami G, Kiani A (2006) Sensitive high-performance liquid chromatographic quantitation of gabapentin in human serum using liquid-liquid extraction and pre-column derivatization with 9-fluorenylmethyl chloroformate. J Chromatogr B Analyt Technol Biomed Life Sci 835: 123-126.

14. Krivanek P, Koppatz K, Turnheim K (2003) Simultaneous isocratic HPLC determination of vigabatrin and gabapentin in human plasma by dansyl derivatization. Ther Drug Monit 25: 374-377.

15. Chang SY, Wang FY (2004) Simple and sensitive liquid chromatographic method with fluorimetric detection for the analysis of gabapentin in human plasma. J Chromatogr B Analyt Technol Biomed Life Sci 799: 265-270.

16. Wolf CE, Saady JJ, Poklis A (1996) Determination of gabapentin in serum using solid phase extraction and gas-liquid chromatography. J Anal Toxicol 20: 498-501.

17. Kushnir MM, Cossett J, Brown PI, Urry FM (1999) Analysis of gabapentin in serum and plasma by solid-phase extraction and gas chromatography-mass spectrometry for therapeutic drug monitoring. J Anal Toxicol 23: 1-6.

18. Borrey DC, Godderis KO, Engelrelst VI, Bernard DR, Langlois MR (2005) Quantitative determination of vigabatrin and gabapentin in human serum by gas chromatography-mass spectrometry. Clin Chim Acta 354: 147-151.

19. Gambelunghe C, Mariucci G, Tantucci M, Ambrosini MV (2005) Gas chromatography-tandemmass spectrometry analysis of gabapentin in serum. Biomed Chromatogr 19: 63-67.

20. Matar KM, Abdel-Hamid ME (2005) Rapid tandem mass spectrometric method for determination of gabapentin in human plasma. Chromatographia 61: 499-504.

21. Ramakrishna NVS, Vishwottam KN, Koteshwara M, Maroj S, Santosh M, et al. (2006) Rapid quantification of gabapentin in human plasma by liquid chromatography/tandemmass spectrometry. J Pharm Biomed Anal 40: 360-368.

22. Ifa DR, Falci M, Moraes ME, Bezerra FA, Moraes MO, et al. (2001) Gabapentin quantification in human plasma by high-performance liquid chromatography coupled to electrospray tandem mass spectrometry. Application to bioequivalence study. J Mass Spectrom 36: 188-194.

23. Ji HY, Jeong DW, Kim YH, Kim HH, Yoon YS, et al. (2006) Determination of gabapentin in human plasma using hydrophilic interaction liquid chromatography with tandem mass spectrometry. Rapid Commun Mass Spectrom 20: 2127-2132.

24. Carlsson KC, Reubsaet JL (2004) Sample preparation and determination of gabapentin in venous and capillary blood using liquid chromatography-tandem mass spectrometry. J Pharm Biomed Anal 34: 415-423.

25. Park JH, Jhee OH, Park SH, Lee JS, Lee MH, et al. (2007) Validated LC-MS/ MS method for quantification of gabapentin in human plasma: application to pharmacokinetic and bioequivalence studies in Korean volunteers. Biomed Chromatogr 21: 829-835. 